\title{
TRANSFORMING THE NARRATIVE ELEMENTS FROM THE FITZGERALD INTO FINCHER'S THE CURIOUS CASE OF BENJAMIN BUTTON
}

\author{
Suryo Tri Saksono, Ana Rahmawati
}

\author{
Email: suryo_tri@yahoo.com \\ Program studi Sastra Inggris Universitas Trunojoyo Madura \\ Alamat Korespondensi: Jl. Jeruk 2 No 16 Kamal, Bangkalan 69162
}

\begin{abstract}
Adaptation is the process of transforming one form of art into another one. Many decent films are adapted from great literary work. In the adaptation process, some changes occur in film. It is because film is produced in different way from novel. This study focuses on the transformation of the narrative elements from the short story into the film entitled The Curious Case of Benjamin Button. This study uses the theory of adaptation by Linda Seger to explain the adaptation process from the short story into the film as the sources of data. There are three processes of adaptation: condensing and expanding the material, the process of making the film commercial, and varied changing. The narrative elements theory is also used to explain the structure that builds the literary work.
\end{abstract}

Keywords: Short Story, Film, Narrative Elements, Adaptation.

\section{INTRODUCTION}

The process of changing written literary work into film is called as film adaptation. Adaptation is a transition, a conversion from one form of art into another form. It transforms one medium to another medium (Seger, 1992:2). Film adaptor is like the sculptor, Michelangelo. When he was asked how he able to carve such a beautiful angel, he replied that "The angel is caught inside the stone. I simply carve out everything that isn't angel." It goes the same with the adaptor. The adaptor is sculpting everything that isn't film. It can be understood that the intrinsic of film contained within another medium remains (Seger, 1992:2). Its intrinsic element lies within the audio-visualization to deliver the message.

This study studies about the process of adaptation from a short story into a film entitled The Curious Case of Benjamin Button. The short story was written in a jazz age era by Fitzgerald. The jazz age era is the post WWI era in which American people experience rapid social changes both socially and economically. This movie has been nominated in several awards. The film received thirteen Academy Award nominations and was also nominated for five Golden Globe awards. Actually, both short story and film differ in almost all aspects of narrative elements except in the idea of a man that reversed aging. Hence, the transformation of narrative elements in the short story into the film is very interesting to be studied. The transformation brings a very different soul from the original work.

As the adaptation process is reflected through the narrative elements transformation in The Curious Case of Benjamin Button, the adaptation theory is used to reveal the adaptation process from short story into film. The process of adaptation involves condensing and expanding, making it commercial, and varied changing. Through those processes the adaptor should aware that the written literary work is intrinsically different from the characteristics of film (Seger, 1992:2).

There have been a number of studies of adaptation process from written literary 
work into film (Putri, 2012; Joesaar, 2007; Sardjana, 2008). All of which present the process of adaptation happens in the structure of the works. However, none of these studies provides an explanation about the cause of the transformation occurs in it. While there has been a research on the film The Curious Case of Benjamin Button (Perkasa, 2012), none has been studied about the comparison of the film with the original short story written by F. Scott Fitzgerald. This study is the first study that studying about adaptation in The Curious Case of Benjamin Button. This study is different some aspects. Firstly, this study finds the narrative elements of both sources of data. Secondly, it explains the transformation process from short story into film.

\section{STUDY FRAMEWORK Adaptation}

The process of altering literary work into film is called as adaptation. Adaptation is a transition, a conversion from one form of art into another form. It transforms the medium to another medium (Seger, 1992:2). Adaptation is not only using novels and film. In the Victorians era, people adapt everything. The stories of poems, novels, plays, operas, paintings, songs, and dances were adapted to another medium (Hutcheon, 2006: xi).

Adaptation means changing. The process of changing involves rethinking, reconceptualising, and understanding. Through those processes the adaptor should aware that the written literary work is intrinsically different from the characteristics of film (Seger, 1992:2). There are three process of changing in adaptation theory by Linda Seger. This process related to the transformation of the elements that build the story. Those processes are condensing and expanding the material, making it commercial and varied changing.

\section{Condensing and Expanding the Material}

The condensing or cutting process involves losing subplots, combining or cutting characters, leaving out several themes, and finding the dramatic line. These processes can be frustrating for the adaptor since they have to give up scenes and characters they love. The adaptor must consider first which elements fit to the film (Seger, 1992:2-3).

\section{Making the Film Commercial}

The transition from literary work into film requires that the material can be accessed by the general public since literary work and film has varies audience. To make the film more marketable, there are some steps that can be taken by the adaptor. Strengthening the story line is a good step since audiences like a well-told story. A good story has movement and focus and engages audiences from beginning to end. The next step to make the film commercial is creating a likeable, sympathetic, and identifiable character. The other step is changing the endings. Furthermore, the adaptor usually adds a car chase and a sex scene as a lowest common aspect to appeal audiences (Seger, 1992:4-5).

\section{Varied Changing}

The adaptor usually makes changing for dramatic purpose. Changes are important to make transition into another medium. Changes the setting from Maryland into New York, changing the character, changing the train to a ship, or creating an orphan house instead of family is important for the dramatic purpose. Therefore, making variation in film is important to create a dramatic purpose. The varied changes in the film may cause the changes on theme and message of it. The varied changes may also happen because the film maker wants to make something that different at all with its original work (Seger, 1992:8).

\section{NARRATIVE ELEMENTS Plot}

Plot is understood as the connecting structure of events in certain story. Story can be said as backbone because the beginning and the end are changeable (Forster, 1954:45). It is a narrative of events arranged in their time sequence (Forster, 1954:47).

\section{Character and Characterization}

Since the author is also human being, there is a resemblance between him and his subject matter which is absent in many other forms of arts. The writer makes up a number of word-masses roughly describing himself as 
a human. He gives them names and sex, assigns them plausible gestures, and causes them to speak by the use of inverted commas, and perhaps to behave consistently (Forster, 1954: 70). The characters are characterized through some ways in the literary work. According to Kenney there are three classifications of the characters portrayal methods, the discursive, the dramatic, and the contextual (1966:38). There several kinds of characters, those are flat character, dynamic character, major character, and minor character (DiYanni, 2001:55).

\section{Setting}

Setting refers to when and where something happen. The series events in plot are created to be happening at some time and somewhere. According to Kenney about the types of settings, there are neutral and spiritual settings. The neutral shows the real physical environment to the reader such as grass, land, sky. The physical setting implies the spiritual setting inside it (1966:39). There are four elements of setting.

\section{Point of View}

According to Jones in his book entitled Outlines of Literature, there are four main types of point of view. They include the first point of view, third person point of view, omniscient point of view and limited omniscient point of view (Jones, 1968: 29).

\section{Theme}

A theme is the central idea or ideas explored by a literary work. A theme influence on how the story is being told, in what way the story is understood. Theme is the story aspect in line with meaning. Theme makes the story focused and united. The beginning and the end will be match and contended because of the theme (Stanton, 2007:37).

\section{DISCUSSIONS}

\section{Condensing and Expanding the Material}

The Curious Case of Benjamin Button adapted from 1920's Fitzgerald short story with the same title. The process of adaptation causes some condensing and expanding the material from short story in all of its narrative elements, such as plot, characters and characterization, setting, point of view, and themes. All of the elements are described in the following sub sub-chapters:

Plot

The story begins with the startling condition of baby Benjamin in which forces the father to buy him clothes. This part is omitted in the film. Compared to the condensing, the process of expanding happens more in the film. The beginning of the film is extended into the old days of Daisy Fuller and her daughter. The story of Benjamin is told through an old diary of Benjamin that is read by her daughter Caroline. The story of the clockmaker who lost his son in a war also added to give a background on Benjamin's reversed aging case.

In the next part that is complication, the process of condensing and expanding the subplot keep going. The main conflict in the short story is that Benjamin is born as an old man. Side conflicts include his father's resistance to this strange situation and the social stigma of being abnormal. This part is omitted in the film because the film does not use any set which is related to the social environment in which Benjamin grows. Instead of the social environment, in the film, Benjamin is portrait to live in the Nolan House, a place for the elders who are near to death. Benjamin is treated same as other elders, so there is no confusion or social rejection upon his existence.

Meanwhile, one important time of human's life which is condensed in the film is the time for school. The part of Benjamin goes to school is omitted in the film because the film does not employ anything about Benjamin's interaction with the people outside of the Nolan house. The different physical appearance of Benjamin in the film and the short story also becomes one of the reasons of condensing process. At five, Benjamin in the film cannot walk even stand by himself. It is made intentionally because there will be no one take care of Benjamin in school.

The next part of the film experiences more expanding. Benjamin in the film lives more adventure in life rather than Benjamin in the short story. The film brought the story of journey on the tugboat while the short story does not. This is done to make the film 
more alive and interesting to the viewer. The film also makes the love story of Benjamin as the main story of the film while the short story makes the love story just simply as one of human's experience in life. This is causes the short story has a different genre with the film. Since the film is centred on the Benjamin's love story with Daisy, the complication between them also added to add the tension of Benjamin's life.

The denouement also experiences transformation into expanding and condensing the material of the plot. After the marriage to Hildegarde, the short story is filled with a sense of falling action until his death. The end of short story is led by some parts related to Benjamin who is not only getting younger but also achieves many things. Meanwhile, the denouement part of the film is expanded into different way. After deciding to leave Daisy and their child, Benjamin goes abroad. He goes around the world. The rest of his life is spent from one place to another place. Until one day he appears as a teenager. The ending shows the process of Benjamin gets younger day by day and dies on Daisy's lap in the end. The very end of the film shows the picture of the clock which still runs backwards in train station's storage room. This part is emerged as in the beginning that explains why Benjamin is born on unusual condition.

\section{Characters and Characterization}

Even the short story and the film have the same title yet both of it contains very different characters. The same character with the same name in both short story and film is only Benjamin Button. Based on the previous discussion, since plots are very different, it brings consequences to the other element that is characters and characterisation.

The major characters that are brought to the film are expanded to make a wider scope of story line. The short story only contains few characters to present, therefore the film adds some major characters to support the story line expanding. The short story only has one major character that is Benjamin while the film has some major characters. The characters that are vital to the development and resolution of the conflict are added because the story line of the film is expanded.
Compare to the transformation of major characters, the process of condensing minor characters in the short story can be seen clearly. Those changes result the absent of some minor characters. These minor characters are omitted because their existence is not significant and match with the film story line.

\section{Setting}

The changes on the plot and subplots convey impact towards other elements including settings. The process of expanding is more prominent in the film because the short story's settings are not sufficient to be brought to the film. There are limited places and times established as the settings of the short story. Those settings are not adequate to produce a film with more than two hours length. Another reason of expanding is also because the modification on the plot as what has been discussed in the preceding subchapter.

\section{Point of view}

The point of view in the film is more likely to expand. There is only one point of view in the short story. The short story uses omniscient point of view. The narrator tells everything from his side. It can be known that the narrator knows everything including all character's mind, minor or major. "I shall tell you what occurred, and let you judge for yourself" (Sh.CE.PoV.P1). The narrator using pronoun I but he is not involved in the story. He becomes omniscient but knowing all things in the story.

It is very different with the film. The Curious Case of Benjamin Button served the story from each character's side. It causes the film has many point of view. The film shows the point of view from all characters that exist in the film itself. Most of the film is told from Benjamin and Daisy's point of view. The film begins with old Daisy that asks her daughter to read a journal of someone. The next scenes of the film are told alternately using Benjamin and Daisy's narration. Every time the audiences watch the scene played by certain character, it can be found that each character tells the story from their own point of view. 


\section{Theme}

The theme is the underlying moral values of the story. The theme of the short story describes opinion about life, human nature or elements of the society. However, the themes of the short story, just like other elements of the story, are more likely to be expanded rather than cut. Nevertheless, there are several themes that are condensed in the film.

The first is about individual versus society. This theme in the short story presents how Benjamin faces society's denial upon his existence. Another point is that the theme about revenge occurs in the short story because Benjamin feels an injustice. He makes revenge toward Yale College that previously rejected him to enter the college. Overcoming problem in life is one of the condensed themes in the film. Benjamin in the film can accept a tough situation and turn it into triumph. Those themes are condensed in the film since it does not match with story line of the film.

The themes in the film are more various than in the short story. The loss of innocence becomes one of the themes. This theme is about the development of the character from young into old, or teenage into adult. Another expanded theme in the transformation process is type of character. In the film, Benjamin meets more people with a different character than in the short story. Divinity becomes another expanded theme. Human always tries to understand and believes God. On the other hand, the satisfaction is elusive and difficult.

\section{The Process of Making the Film Commercial}

Money is the foremost motivation of the filmmaker to adapt certain literary work as in The Curious Case of Benjamin Button. There are four processes done to make the film commercial. The two most noticeable processes are strengthening the storyline and making the sympathetic, likeable, and identifiable characters. The other two processes are making the sex scenes and changing the ending. Those processes are important to attract viewer's attention. It is done to make the film becomes more popular and gain much profit to the filmmaker.

\section{Strengthening the Storyline}

First of all, to strengthen the story line, the filmmaker adds information about the background of Benjamin's case. As what have been discussed in the previous subchapter about plot expanding, there is a story about Mr. Cake who lost his son in a war. He makes a clock that running backwards. This part of the film strengthens the reason of Benjamin's case. Likewise, to engage the story and remind the audiences about the clock, the film is closed by the story of the clock again. The story of work must be based on actions and reactions, cause and effect. Mr. Cake's hope of his son coming back home by making a running backwards clock is represented by Benjamin reversed aging. It is an important point of the film that if it is omitted will reduce the strength of the story line. It is important to lead the audience from one point to another point. The existence of the clock is important to make sure each scene leads believably to the next part of the story.

Furthermore, a strong story line must have emotional tension. The way of the filmmaker describe the struggle of Benjamin in life adds the emotional tension of the film. The filmmaker puts several obstacles to Benjamin's life on the way he lives his life. Thomas Button's death is another emotional tension in the film. Benjamin's father confesses that he throws Benjamin away when he is still a baby. Benjamin's father also tells that he will die soon and he will give all of his wealth to Benjamin.

\section{Making the Sympathetic, Likeable, and Identifiable Characters}

Audiences like to cheer for the protagonist while watching film. Audiences tend to identify the characters resemble to them in some ways. For example, characters also play certain roles in a family; do certain types of work, concern about things people usually concern about. Apparently, characters not only have to resemble audiences but also have to be generated its initial sympathy as the protagonist. It is done to the character Benjamin Button in the Film. Benjamin in the short story has a very different personality. The way he is brought to the film also differs in some ways. Benjamin in the film is included into sympathetic, likeable, and identifiable character. 
To build this type of characters, first of all can be applied into his physical descriptions. Basically, the most interesting part of the story is that Benjamin who is reversed aging. Benjamin is born as baby but with physical characteristics of a man of eighty. The baby is nearly blind of cataract. His bones are severe arthritis. His skin is loss its elasticity. In conclusion the baby is just born but he looks like a man of eighty near to death. Despite send him to the police, Queenie decides to take care of that baby. By looking this description the audiences will definitely give sympathy to this character.

Moreover, the audiences are served with the physical changes of Benjamin Button. The film shows Benjamin from the first as a baby, an old man on wheelchair, an old man with a cane, a crooked old man, a middle age man, a young man, a teenager, a boy, until a healthy baby in the end. The audiences can easily identify the main character through his detail physical changes. The climax of the story which occurs at the time Benjamin in his forty with perfect physical appearance is the most noticeable physical description of Benjamin.

To raise the commercial aspect of the film, the filmmaker make Benjamin character to be played by Brad Pitt. As what people already known that Brad Pitt is the popular Hollywood actor that won several awards. It will be different if the character played by another actor. It is also supported with the make-up of done on Benjamin. It is not easy to create physical changes on someone from old into young.

Additionally, altruism is another characteristic of this type of character. The character that has an unselfish concern for the welfare of other will get more sympathy from the audiences. The character is also admired because they take action to suffer of someone else. At the time Benjamin wants to tell Daisy about his father's death in New York, Daisy leaves him for another man. However, Benjamin sees Daisy in Paris when she gets an accident even Daisy has ignored him before. Benjamin is there, where Daisy needs someone.

In addition, being a victim can touch the audiences. Benjamin is the victim of his father action. Benjamin's father, who suffers from losing his wife because of Benjamin, decides to kill Benjamin. Fortunately there is a police that almost catch him when he wants to throw Benjamin to the river. Finally Benjamin is ended at the old folk's home that is Nolan house. Benjamin grows without his real mother as in the short story. Benjamin in the film is motherless but is not lack of affection.

In Addition, Sympathetic character in the film should be loved by someone else. Benjamin in the film gains loves from many people. The main focus of the story of course is between Benjamin and Daisy. Besides that Benjamin is loved by the people around him likes Queenie. Queenie is his beloved mother who is willing to take care of him since he is a baby. She takes care of him while nobody else willing to keep him even his father. However, in the end Benjamin have to suffer from losing the people he loves.

\section{Making the Sex Scenes}

The love story of Benjamin and Daisy is told in detail as the focus of the story. It is very different with the short story. Benjamin in the short story is only interested in Hildegarde when she is still young woman. There is no detail about Benjamin love story with Hildegarde. The existence of woman in Benjamin's life in the short story is not so significant to the story line. In contrast, Benjamin's life in the film is built around women. Their love story is appeared in many making love scenes. This is one of strategies to make the film get a public's attention. Here are the findings on sex scenes in the film.

The very first sex scene is between Benjamin and the prostitute in the whore house. This the first sex experience of Benjamin. Benjamin's first sex experience is just like another people, it is interesting. This kind of experience becomes a commodity in entertainment industry to be sold. The other sex scene occurs during Benjamin's journey with Captain Mike on the tugboat. Benjamin unintentionally meets this woman in a hotel. This one is the scene when Benjamin feels for the first time that he is loved. It happens in Winter Palace hotel in Russia. Their relationship is an affair since Elizabeth is a married woman. The affair between adults is sometimes happen in life and it is interesting to be told. There are also illustrations about Benjamin's relationship with two or three 
women. These are the adventures of Benjamin on women.

The most noticeable sex scene is the first sex scene between Daisy and Benjamin. It is a desire that has been delayed for thirty years. They meet at their perfect age. Both of them are in their forties. They have been through many things before come to this moment. After their first meet, Benjamin asks Daisy to sail with him. They go to Florida Keys; to the Caribbean, and many places. They are falling in love each other and live passionately. The making love scenes of them seem never be enough. They make love on a sailing boat, under the sky, on a beach, in a hotel. The scenes below are the most noticeable sex scenes in the film. It can be noted as the climax of the story. This is the last sex scene between Benjamin and Daisy. Sexual desire, habit, activity is a worth commodity to be sold. In Hollywood movie industry like, sex scenes always becomes the most important part to raise the commerciality of the film.

\section{Changing the Ending}

Most people like to watch happy ending. But actually it depends on where the film is produced and what kind of audiences it has. The American people like to watch happy ending. It is applied in the film even it is not really a happy ending. In happy ending usually it is told that the main character's live happily ever after. While the film is not like that even both Benjamin die. Compared to the short story the film's ending is happier. In the end Benjamin dies on Daisy's lap, the woman he loves. In the short story Benjamin dies on his nurse's lap. By changing the ending, it is hoped that the ending will bring more emotional atmosphere towards the audiences. Since this film is also included into American film, the pattern of its ending resemble with the American film ending. It tends to be happy ending. Even in the end Benjamin should die, but at least he dies on the lap of woman he loves.

\section{Varied Changing}

Varied changes done in the film for dramatic purposes. The filmmaker should create the structure and the dialogue of the film to produce a conflict that will hold the attention of the audiences, and evoke a progressively strong emotional response in a short space of time. A film only has around two hour's length. The adapted film The Curious Case of Benjamin Button experiences some changes for dramatic purposes. The process of changing is done in all elements of the story from plot until theme.

\section{Plot}

The varied changing of the plot is done to create a dramatic atmosphere of the story. Benjamin in the film is thrown away by his own father. It is because Benjamin father thinks that baby Benjamin is a monster. Besides his terrible appearance as a baby, Benjamin's father thinks that his wife dies because of him. This leading initial situation of Benjamin's life is changed from the short story. The different case happens in the film. Benjamin's father in the film decides to throw the baby away right after his birth.

Eventhough both Benjamin's father in the short story and the film are the same in case of cannot accept their son peculiarity, Benjamin's early life is more dramatic in the film. This is how the filmmaker creates a strong emotional feeling towards the audiences to begin the film. His father tries to kill him by throwing him into river. Benjamin's father close to throw the baby to the river but he does not have heart to kill him. Fortunately, there is a police sees him and calls him. Benjamin's father is caught by surprise and runaway.

Furthermore, after being dumped by his father, Benjamin in the film is ended in an old folk's house that is Nolan house. Benjamin's early life is changed from living in his own family house into old folk's house. Benjamin's childhood in the short story is spent in his family's house. He is taken care by his father. He lives in a prosperous condition. Even so, actually Benjamin in short story is lack of love and attention from his surroundings. Meanwhile, Benjamin in the film lives in a poorer condition but he is not lack of affection. Everyone in the Nolan house is in the different age, but they are in the same physical condition. It makes Benjamin more acceptable. He is seen as same as the other occupant of the house. He is loved and cared as the same human being. Benjamin's existence is not exposed to the society. The 
people around him sees him is united with the Nolan house.

Furthermore, the changes are done on Benjamin's love story. Due to what has been discussed before that Benjamin's love story is the main focus of the film, Benjamin faces more problems in his love story in the film. On the other hand, Benjamin's love story in the short story almost faces no problem except the denial from Hildegarde's father and society's judgment on him. More tragic and romantic love story occurs to Benjamin in the film. Benjamin firstly meets Daisy when she is a little girl. Their love story not even gets any better when they are adult. They need a very long time to be together in the end. They have to wait for more than thirty years before they can live as a couple.

In the end, Benjamin's love story in the film and the short story is ended in a different way. Benjamin's love story in the short story does not give a significant role towards Benjamin's life while in the film Benjamin's life is built around his love. In the short story Benjamin's love to Hildegarde is reduced along with her aging. Benjamin's wife moves abroad in the rest of Benjamin's life and she disappears from the story later on. Their love story ended just like that without any romance.

On the other hand, Benjamin's love story ending in the film is dramatic. After meets Daisy and live together, they have a daughter. They live a very happy life until then Benjamin thinks that he cannot be a real father for their daughter. He has to leave Daisy and their daughter because Benjamin does not want to burden them with his reversed aging. He does not leave her because he does not love her anymore. Instead he sacrifices himself for her happiness. Benjamin even says that he loves daisy's wrinkles. But actually, Benjamin's love story with Daisy is not ended at all. They still love each other even after Benjamin's going. They are separated for a longtime but they are united again in the end. Even not as couple again but more likes a mother and a son. Daisy takes care of Benjamin who is suffering from dementia and becomes a little boy in the end. This is a story of true love.

\section{Characters and Characterization}

There are many changes on the characters of the film. Basically, the characters in the short story and the film are different at all. The one that remains the same is Benjamin Button.

There are some changes done on the major characters. The first character that is changed is Benjamin's father. In the short story his name is Roger Button while in the film is Thomas Button. They are characterized as a different person. As what has been discussed before that Roger Button is willing to take care of his son while in the film Thomas Button does not willing to take care of him. Roger Button is such a good father.

As the main character, Benjamin also characterized in different way in the film. First of all, Benjamin in the short story is born as a man of seventy. He is definitely described as old man. It becomes an impossible thing in the real world that a person that just born has a beard and eight inches tall. On the other hand, Benjamin in the film is more make sense to the audiences. Benjamin in the film also has an ability of speak, read, and analyze from the first time he is born. He is born as a real man of eighty who loves to read an encyclopedia rather than play toys. Benjamin is born as a baby but with the physical characteristics of man of eighty. He is described as such a pitiful baby. Benjamin in the film grows normally as child which has no ability to do anything. He learns to speak and read step by step.

The other major character that is changed from the short story into the film is Benjamin's woman. In the short story the name of Benjamin's woman is Hildegarde Moncrieff while in the film is Daisy Fuller. Both of them are characterized in a different way. Hildegarde is a common woman and in the end only becomes a housewife. On the other hand Daisy is an active woman. She is a ballet dancer. There is no detail about Hildegarde's life and she is insignificant towards Benjamin's life. Moreover, Daisy's existence is very significant towards the whole story.

Furthermore, the changes are also done on the minor characters. The first is Benjamin's child. In the short story Benjamin has a son named Roscoe Button while in the 
film Benjamin has a daughter named Caroline. Benjamin raises Roscoe by himself. Roscoe is characterized as a son that does not love his father so much. He thinks that his father is just bothering. Roscoe treats him not so well. Roscoe does not want his father will give a scandal to his family. He is such a cruel son for Benjamin. One day when Benjamin ask him to send him to prep school, he rejects and angry to him. Benjamin is treated in a bad way by his own son in his old days.

The other minor character that is changed is the doctor who helps Benjamin's birth. In the short story the doctor is Doctor Keene. He is a family doctor. Doctor Keene in the short story can be said as unprofessional doctor. It is because he feels irritated toward Benjamin who is different from other baby. A real doctor should not act in that way. A more professional doctor is shown in the film. In the film the doctor that helps Benjamin's birth is such a good doctor. He calms Thomas Button down to anticipate what is coming to him. There is also Doctor Rose who helps Queenie to investigate Benjamin's physical condition. As doctor they give an objective view of a doctor. Doctor Rose for instance gives an explanation about the baby's condition he just not runs away from him as what Doctor Keene does.

\section{Setting}

The time of Benjamin's birth in the short story is different with in the film. Benjamin in the short story is born in 1860 and dies in 1927. The writer confess himself has created an anachronism of the story.The short story represents the jazz age in America in the early $20^{\text {th }}$ century. This age was the time post WWI in which American people experienced significant social changes. On the other hand, the film does not bring the jazz age characteristics at all. Benjamin in the film is born in 1918 and dies in 2003. It makes the film goes to the $21^{\text {st }}$ century social condition.

Furthermore, the place where Benjamin lives is also different. In the short story Benjamin lives in Baltimore. Baltimore is located in Maryland. It is the largest city there. And the 24th largest city in U.S. The story itself is not synchronic. It is clear that the story is written in different era with the story in the short story. The language that is used is different with the language that is used too often in this day and age.

In the part one, when Roger Button learns of his difficulty and while imagining of taking Benjamin home in his mid, he goes through a slave market and has a cruel idea. Mr Button wanted suddenly that his son was black. There's nothing that looks cruelly racial in the story; however someone going into the story without a mind-set for the setting might be knocked off kilter to read such plain references to slavery. Meanwhile Benjamin in the film lives in New Orleans. It is located in Louisiana. New Orleans is well known for its distinct French Creole Architecture. New Orleans was formerly the colony of French. The description of this town is described in detail and synchronic with the exact condition of New Orleans in the film.

Benjamin in the film is born in Maryland private hospital while in the film he is born at his family house. Later, Benjamin in the film is not raised by his own family but by Queenie in Nolan House. Choosing a match setting is more difficult rather than choosing the human characters. Nolan house can be considered as a character of the film. The house itself is made to make the process of Benjamin reversed aging looks real. The film is a fantasy and it has to make the audiences believe in that fantasy. Each moment and each scene in the film must be believable. Nolan house actually exists, to make the film more believable the house even decorated for several times. The adaptor uses different curtains for each time period.

Additionally, another setting that is changed is the place where Benjamin meets his love. In the short Benjamin meets Hildegarde in the Shevlin's Country House. They have a ball party there. The place where they meet is made in the ball because it is suitable with the setting of condition in which Fitzgerald put. The short story is included into jazz age short story. It is portray the condition of American people who experience significant social changes. Ball party is a part of society's habits at that time. They go to the ball to get know each other well. They go out socially through ball party. Meanwhile Benjamin in the film firstly meets Daisy in the Nolan house. It is the place where everything begins and ends. 
The social setting of the film is also different with the short story. The Baltimore society has a bad impression towards Benjamin's case. Baltimore society is a kind of society that likes to gossip another people's life. Baltimore society likes to stay on another people's business. They do gossip when Benjamin gets marry with Hildegarde. It is very different with the social setting in which Benjamin grows in the film. Benjamin grows in a peaceful social condition. Benjamin lives in diversity. In the house black people and white people live together in peace. It is different in the short story which still contains racial differences.

The company owned by Button's family is different company. In the short story Roger Button own s the Roger Button \& Co., Wholesale hardware. It sells building material and hardware. Meanwhile in the film Thomas Button owns Button's button. It is a button factory. It is made as button factory because the condition is suitable with New Orleans condition. New Orleans is well known as the producer of cotton and it has a close relationship with textile production including button. Button's factory supplies the needs of button for military uniform during war. Moreover, the war in the short story and in the film is also different. In the short story the war that happens is Spanish-American war while in the film it is World War II.

\section{Theme}

The theme of the film is changed in some aspects. The first theme is about man struggle against nature, society, and himself. Benjamin Button is always at battle with human nature, whether the drives described are sexual, material, or against the aging process itself. The sexual drives on Benjamin's life in the short story and the film are changed. Benjamin's sexual drives in the short story are not described in detail as in the film. Meanwhile the film shows Benjamin's sexual drives with many women he meets. The struggle of Benjamin related to the material also differs in the film. Benjamin lives a prosperous life in his rich family while Benjamin in the film has to struggle a lot to survive in line with material.

Furthermore, Benjamin in the film is unusual case on Benjamin's aging process is the biggest struggle that Benjamin should face. As the result of his special case, Benjamin has to face pressure from his surroundings. Mankind is always struggling to determine if societal pressure is best for living. In the short story Benjamin should face an apparent denial from the society about his special case. Meanwhile in the film Benjamin has to do more struggle against himself.

The other changed theme is the importance of family. The importance of the family in the short story is extended in different way in the film. The importance of Benjamin in the short story has a different meaning with in the film. Benjamin in the short story merely means a family member that should be taken care and raised.

Furthermore, love as the worthiest of pursuit is changed in wider aspect in the film. As what has been discussed before that love story is the main focus of the film while it is not the same with in the short story. Love is only a little part of Benjamin's life. Love is only the complementary in Benjamin's life cycle. Normal person will fall in love, marry, and make a family. This simple definition of love story is happen in Benjamin's life in the short story. Meanwhile, in the film, Benjamin's struggle in life finally is to chase after his love. So, love is part of the most precious of pursuit in the film.

In addition, death as a part of the life cycle is the theme of both short story and film. Normally, human is born as a baby and die as an old man. This is actually the basic theme of the story. Fitzgerald wrote this short story inspired by Mark Twain's who is said that it is a pity that the best part of life comes at the beginning, and the worst part at the end. Because of that Fitzgerald was inspired to write a story about a person that reversed aging. Whatever the story is, the life cycle will always run as what it is. People will die in the end of their life. The different aspect of the short story and the film in this case is that the process of reversed aging in the film is more normal. Benjamin in the film is born as a baby who can do nothing except crying. Meanwhile the short story tells that Benjamin who is just born is eight inches tall and has a beard as a real old man.

\section{CONCLUSIONS}

In this final chapter, the conclusion is made related with the research problems of 
this study. The research problems cover the process of adaptation; expanding and condensing the material, making the film commercial, and varied changing. After analyzing the short story and the film, The Curious Case of Benjamin Button, it can be concluded that the film experience many changes including condensing and expanding the material, making the film commercial, and varied changing.

There are thirty processes of condensing and forty five processes of expanding the material. The processes involve all aspects of narrative elements of the film; plot, characters and characterizations, setting, point of view and themes. The processes on condensing and expanding the plot involved adding and losing the subplot of the short story and the film. The processes of condensing and expanding the characters involve major and minor characters. The setting is also condensed and expanded into various kind of geographical, social, and time setting. The point of view experiences more expanding rather than condensing. Moreover, the themes are also more various in the film.
There are thirty three processes of making the film commercial. The processes covers four processes; strengthening the story line, making the sympathetic, likeable, and identifiable character, making the sex scenes, and changing the ending. In strengthening the story line, the filmmaker adds the background of Benjamin's case, and adds the emotional tension. Benjamin Button is characterized in different way with in the short story to create a sympathetic, likeable, and identifiable character. The filmmaker also adds the sex scenes to raise the public attention on the Benjamin's love story. In the end, the ending also changed becomes more emotional in the film.

Finally, there are twenty four processes of varied changing. As in the condensing and expanding the material, varied changing also involves almost all of narrative elements; plot, characters and characterizations, setting, and themes. These processes are aimed to make the film more dramatic so that it can attract the audiences' attention from beginning until the end of the film.

\section{REFERENCES}

Abrams, M. H. 1999. Glossary of Literary Terms (7th ed.). Orlando: Harcourt Brace.

Bakhtin, Mikhail M. 1983. "Epic and Novel". In Holquist, Michael. The Dialogic Imagination: Four Essays. Austin: University of Texas Press.

Bogdan, C. Robert and Sari Knopp Biklen. 1982. Qualitative Research for Education: An Introduction to Theory and Methods. USA: Allyn and Bacon Inc.

Bryman, Alan. \& Burgess, Robert G. 2002. Qualitative Data Analysis. USA and Canada: Rouletge.

Damono, Sapardi Djoko. 2005. Pegangan Penelitian Sastra Bandingan. Jakarta: Pusat Bahasa.

DiYanni, Robert. 2001. The Essay: An Introduction. New York: McGraw-Hill Humanities/Social Sciences/Languages.

Eicar The International Film and Television School Paris. Definition Film. Retrieved From http://www.eicar-international.com/definition-film.html on October 27th, 2012.

Fincher, David (Director), Roth, Eric (Screenwriter). 2008. The Curious Case of Benjamin Button (Motion Pictures). United States: Paramount Pictures. 
Fitzgerald, F. Scott.1920. The Curious Case of Benjamin Button.Pdf. retrieved from http://www.classicly.com/download-the-curious-case-of-benjamin-button-pdf. On 25th September 2012.

Forster. E. M. 1954. Aspects of the Novel. New York: Harcourt, Brace and World Inc.

Hutcheon, Linda. 2006. A Theory of Adaptation. New York and London: Routledge.

Jones Jr., Edward H. 1968. Outlines of Literature.New York: The Macmillan Company.

Kenney, William. 1966. How to Analyse Fiction. USA: Monarch Press.

Kothari, C.R. 2004. Research Methodology (Methods and Techniques). New Delhi: New Age International (P) Limited, Publishers.

Merriam, S. 1998. Qualitative research and case study: Applications in education. San Francisco: Jossey-Bass Publishers.

Miles, Matthew B. and Michael A. Huberman. 1994. Qualitative Data Analysis. London: Sage publications.

Monaco, James. 1981. How to Read a Film. New York: Oxford University Press.

Poe, Edgar Allen. 1984. Edgar Allen Poe: Essays and Reviews. Library of America.

Rotten Tomatoes Official Websites. 2008. The Curious Case of Benjamin Button. Retrieved from http://www.rottentomatoes.com/m/curious_case_of_benjamin_button/reviews/?type=to p_citicson November 10th, 2012.

Seger, Linda. 1992. The Art of Adaptation: Turning Fact and Fiction into Film. New York: Holt Paperbacks Henry Holt and Company, LLC.

Stanton, Robert. 2007. Teori Fiksi (edisi terjemahan oleh Sugihastuti dan Rossi Abi Al Irsyad). Yokyakarta: Pustaka Pelajar

Strauss, A. \& Corbin, J. 1998. Basics of Qualitative Research. Newbury Park: Sage.

Watson, John. 2012. Narrative in Film. Retrieved November 19, 2012 from http://johnwatsonsite.com/MyClassNotes/Topics/Film/FilmNarrative/NarrativeInFilm.h tm

Wellek, Rene and Austin Warren. 1963. Theory of Literature. New York: Penguin Books. 